\title{
CONF-96/202-99
}

BNL-64018

\section{INVESTIGATION OF THE ALTERED LAYER ON ANCIENT CHINESE BRONZE MIRRORS AND MODEL HIGH-TIN BRONZES}

MICHELLE TAUBE* ${ }^{*}$, ALEXANDER H. KING*, AND W. THOMAS CHASE, III ${ }^{\S}$

'State University of New York at Stony Brook, Department of Materials Science and Engineering, Stony

Brook, NY 11794-2275

${ }^{\ddagger}$ Brookhaven National Laboratory, Department of Applied Science, Upton, NY 11973-5000

${ }^{\S}$ Freer Gallery of Art, Department of Conservation and Scientific Research, Smithsonian Institution, Washington, DC 20560

\section{ABSTRACT}
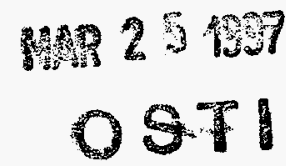

Many ancient Chinese bronze mirrors have a smooth patina. An ingress of corrosion to a depth of approximately $100 \mu \mathrm{m}$ is found beneath the patina. The corrosion selectively replaces the $\mathrm{Cu}$-rich $\alpha$ phase leaving the Sn-rich $\delta$ phase intact. Previous work by $x$-ray diffraction has shown that the $\alpha$-phase replacement product is poorly crystallized or nanocrystalline $\mathrm{SnO}_{2}$. Transmission electron microscopy was employed to further characterize the replacement product in both ancient mirror and replication samples. Nanocrystalline $\mathrm{SnO}_{2}$ in the form of small spheroids has been found. Remnants of an original alloy phase appear to be interspersed with the tin oxide.

\section{INTRODUCTION}

Well-preserved Chinese bronze mirrors have been the subject of scientific research since the early 1930's when interest was piqued by their smooth patinas. ${ }^{1,2}$ Most of the mirrors of interest date from the late Zhou and early Han dynasties. Some Tang mirrors have also been investigated. Chinese mirrors were cast with a typical composition of $70 \%$ copper, $25 \%$ tin and $5 \%$ lead by weight. Bronze of this composition takes on a two-phase microstructure consisting of the $\alpha$ - (Cu-rich) and $\delta$ - ( $\mathrm{Sn}$-rich) phases arranged as $\alpha$-phase needles in a $\delta$-phase matrix. Mirrors have also been reported with $\alpha$ dendrites surrounded by the two-phase eutectoid $^{2}$ which results from a slightly lower tin content.

The color and luster of the mirror surfaces have been the subject of many discussions. ${ }^{1,3-6}$ Distinctions have been made between shiny and matte mirrors and between black and non-black mirrors. One common thread in all discussions is the report of an ingress of corrosion to a depth on the order of $100 \mu \mathrm{m}$ below the shiny patina. In this region, known as the "altered region," the corrosion attacks only the $\alpha$-phase needles leaving the $\delta$-phase matrix intact. Collins called this corrosion "rooted" in the cast alloy.' Several groups have characterized the corrosion product found in the surface regions. ${ }^{2,3,6-11}$ Most of the characterization work has been done with $\mathrm{x}$-ray diffraction $(\mathrm{XRD})$, which yields patterns with broad peaks centered at lattice spacings corresponding to the mineral cassiterite. These results indicate that the surface product contains poorly crystallized or nanocrystalline $\mathrm{SnO}_{2} . \mathrm{SiO}_{2}, \mathrm{Cu}_{2} \mathrm{O}$ and the two alloy phases have also been identified by XRD.

The loss of $\alpha$ in the altered region takes place by a dissolution mechanism through which the copper is selectively removed from the $\alpha$ phase and the tin is incorporated into an oxide. ${ }^{5.7 .812}$ It is possible to predict conditions under which selective dissolution will occur in bronze and thereby replicate the altered region using electrochemical methods. We have reproduced the altered region in two solutions with the application of a constant potential. ${ }^{12}$ The surfaces on the model pieces have been shown to have a similar microstructure and composition to that found on ancient mirrors. ${ }^{11,12}$

In the present work, transmission electron microscopy (TEM) has been used to investigate the altered layer replacement product in both ancient samples and modern replications. Previous TEM work has identified $\mathrm{SnO}_{2}$ in the patina of ancient mirrors. ${ }^{6}$

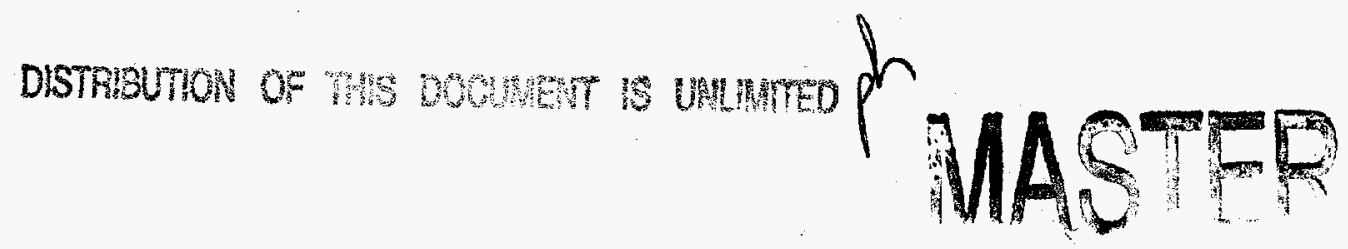




\section{EXPERIMENTAL}

The bronze used to make the model altered layer samples was cast at Brookhaven National Laboratory with $25 \%$ tin by weight. The copper and tin were melted together in a graphite crucible in an induction furnace under rough vacuum. No lead was added. When the metals were completely melted (as observed through a window on the furnace), the melt was poured into a copper chill mold. The samples were annealed at approximately $480^{\circ} \mathrm{C}$ under vacuum for 16 hours.

Two solutions were used for the constant potential treatment: $0.01 \mathrm{M}$ sulfuric acid and $1 \mathrm{M}\left[\mathrm{NH}_{3}+\right.$ $\mathrm{NH}_{4}{ }^{+}$]. The latter was a 1:1 mixture of $0.5 \mathrm{M}\left(\mathrm{NH}_{4}\right)_{2} \mathrm{SO}_{4}$ and $1 \mathrm{M} \mathrm{NH}_{3}\left(63.07 \mathrm{ml} \mathrm{NH}_{4} \mathrm{OH} / \mathrm{L}\right)$. The acid solution was chosen because the ancient samples may have been buried in an acidic soil or purposely treated in acid by the ancient craftsmen. Ammonia was chosen because it is released during the decay of animal remains. The treatments were conducted in beakers. The bronze working electrode was held at a constant DC potential versus a copper pseudo-reference electrode. The choice of potential has been described previously. $^{12}$

Two types of TEM specimen were employed: scrapings and cross-sectional. Scrapings were removed from the surfaces of an ancient mirror and two model bronzes (treated for 48 hours) with a steel scalpel and sprinkled onto formvar-coated TEM grids.

The cross-sectional specimens were made from bronze strips approximately $1 \mathrm{~mm} \mathrm{x} 2 \mathrm{~mm} \times 31 \mathrm{~mm}$ treated potentiostatically for 72 hours. After treatment, short sections were cut from each strip. Two sections treated in the same solution were attached with epoxy with the surfaces that had been facing the counter electrode touching. Once the epoxy had cured, $300 \mu \mathrm{m}$ thick slices were cut off with a low-speed saw. The samples were mechanically polished until nearly electron-transparent. The polishing was done at a slight angle to introduce a wedge into the specimen. Both faces were polished with successively finer grit (to a grit size of $0.25 \mu \mathrm{m}$ ) until the leading edge of the sample had started to recede. Epoxy was used to attach the specimen to a slot grid. The final thinning was done in an ion mill. Figure 1 shows a schematic diagram of a finished specimen.

The microscope was operated with an accelerating voltage of $120 \mathrm{kV}$. The camera length reported by the microscope was checked with polycrystalline-aluminum calibration samples. A diffraction pattern was recorded for camera lengths corresponding to patterns taken of the experimental samples. The ratio of the measured Al d-spacings/known Al spacings was calculated and used to correct the spacings measured in the unidentified diffraction patterns.

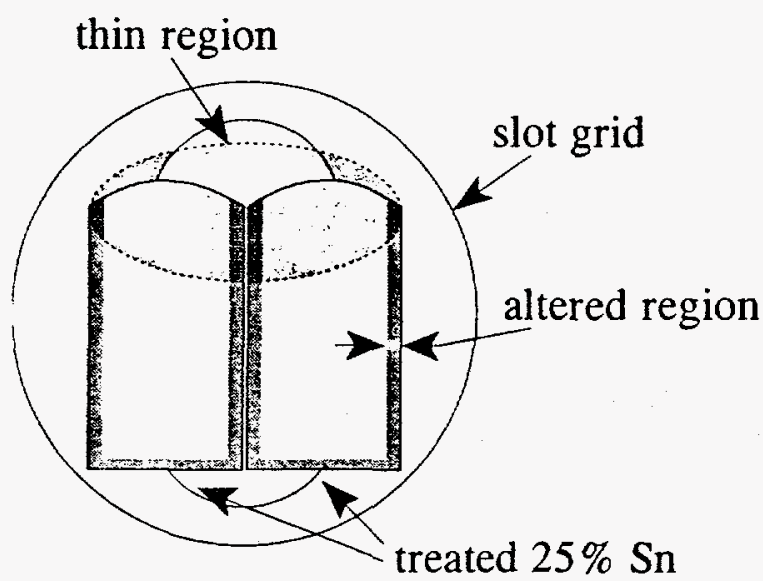

Figure 1. Schematic diagram of finished crosssectional TEM specimen.

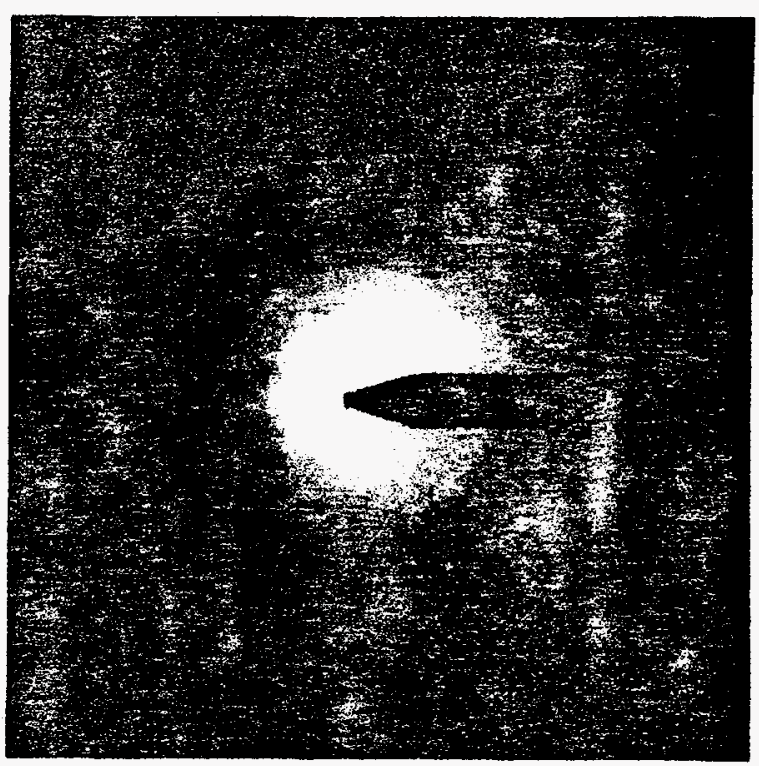

Figure 2. Selected area diffraction pattern taken of fragment scraped from the surface of an ancient Chinese bronze mirror (Freer JCP 25). 


\section{DISCLAMER}

Portions of this document may be illegible in electronic image products. Images are produced from the best available original document. 


\section{DISCLAIMER}

This report was prepared as an account of work sponsored by an agency of the United States Government. Neither the United States Government nor any agency thereof, nor any of their employees, make any warranty, express or implied, or ascumes any legal liabiity or responsibility for the accuracy, completeness, or usefulness of any information, apparatus, product, or process disclosed, or represents that its use would not infringe privately owned rights. Reference herein to any specific commercial product, process, or service by trade name, trademark, manufacturer, or otherwise does not necessarily constitute or imply its endorsement, recommendation, or favoring by the United States Government or any agency thereof. The views and opinions of authors expressed herein do not necessarily state or reflect those of the United States Government or any agency thereof. 


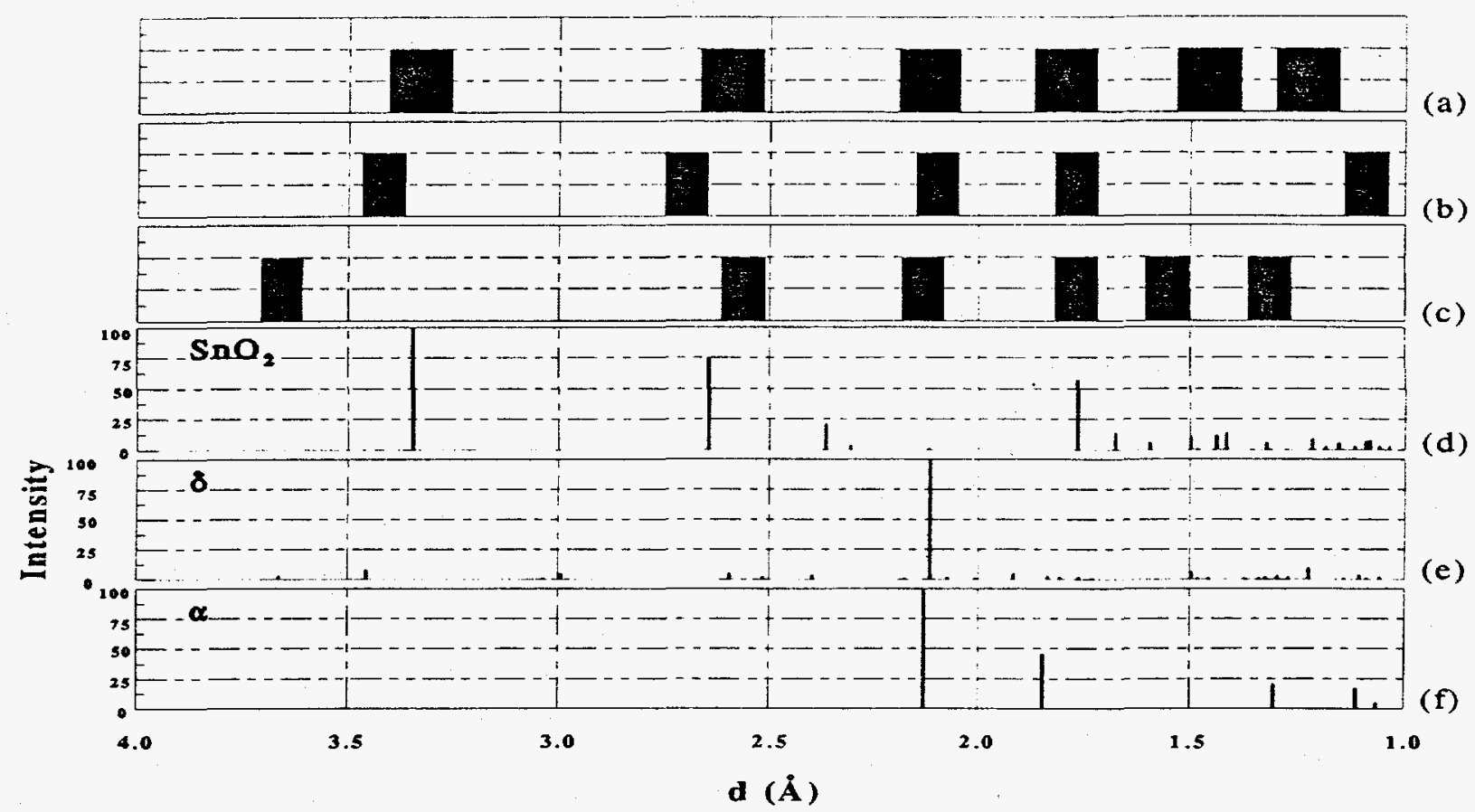

Figure 3. (a)-(c) Graphical representation of diffraction patterns shown in: a) Fig. 2, b) Fig. 8, c) Fig. 10. (d)-(f) Standards: d) cassiterite, e) $\delta$ phase, f) $\alpha$ phase.

\section{RESULTS}

Figure 2 shows a diffraction pattern recorded from a fragment scraped from the surface of an ancient mirror in the James and Carol Plumer Collection at the Freer Gallery of Art (JCP 25). Continuous, diffuse rings can be seen. The d-spacings are shown diagrammatically in Figure 3(a). The width of the lines reflects the precision of the measurements. The published spacings for cassiterite $\left(\mathrm{SnO}_{2}\right)$ mineral (JCPDS 41-1445) are shown in Figure 3(d). The spacings of the diffraction pattern correspond well with the standard. The ring at $2.1 \dot{A}$ has a more dotted appearance than the other rings. Both the $\alpha$ phase and the $\delta$ phase have $100 \%$ intensity (x-ray) peaks near this value: $2.1168 \dot{A}$ for $\delta$ (JCPDS $30-511$ ) and approximately $2.13 \dot{A}$ for $\alpha$ (assuming a face-centered cubic structure with a lattice parameter of $3.69 \dot{A}$ ). The ring probably corresponds to one of the alloy phases rather than the low intensity cassiterite peak. The standard lines for the $\alpha$ and $\delta$ phases are shown in Figures 3(e) and 3(f) for comparison. The intensities shown for the $\alpha$ phase are those of pure Cu (JCPDS 4-836). This fragment was too thick to allow for dark field imaging of the diffracting substance.

Figure 4 shows a bright field image of a fragment scraped from the surface of a sample treated in the ammonia solution. An agglomeration of spheroidal particles can be seen. The largest particles are about $70 \mathrm{~nm}$ in size. A convergent beam diffraction pattern of one of the particles is shown in Figure 5. The spacing of the diffraction spots is approximately $2.3 \AA$ in both, perpendicular directions, which corresponds well with the $2.369 \dot{A}$ spacing of the (200) planes of $\mathrm{SnO}_{2} . \mathrm{SnO}_{2}$ forms tetragonal crystals meaning that the four-fold symmetry of the diffraction pattern would be appropriate for the $(200)$ reflection. Figures 6 and 7 show particles with a similar appearance found in the cross-sectional specimen made from bronze treated in sulfuric acid.

Figure 8 shows a diffraction pattern taken from the region shown in Figure 7 . The d-spacings for the diffraction rings are shown in Figure 3(b). The substance again appears to be $\mathrm{SnO}_{2}$ with a ring at about 2.1 $\AA$. The pointer in the diffraction pattern indicates the diffracted beam used to produce the dark-field inage shown in Figure 9. The spot was on the ring with spacing of $2.1 \AA$. Many small bright spots are visible throughout the image. A spheroid similar to those in Figures 5-7 is also highlighted and is probably a tin oxide crystal because several close diffracted beams were selected by the aperture.

Figure 10 shows another diffraction pattern taken of the acid-treated cross-sectional specimen. The 


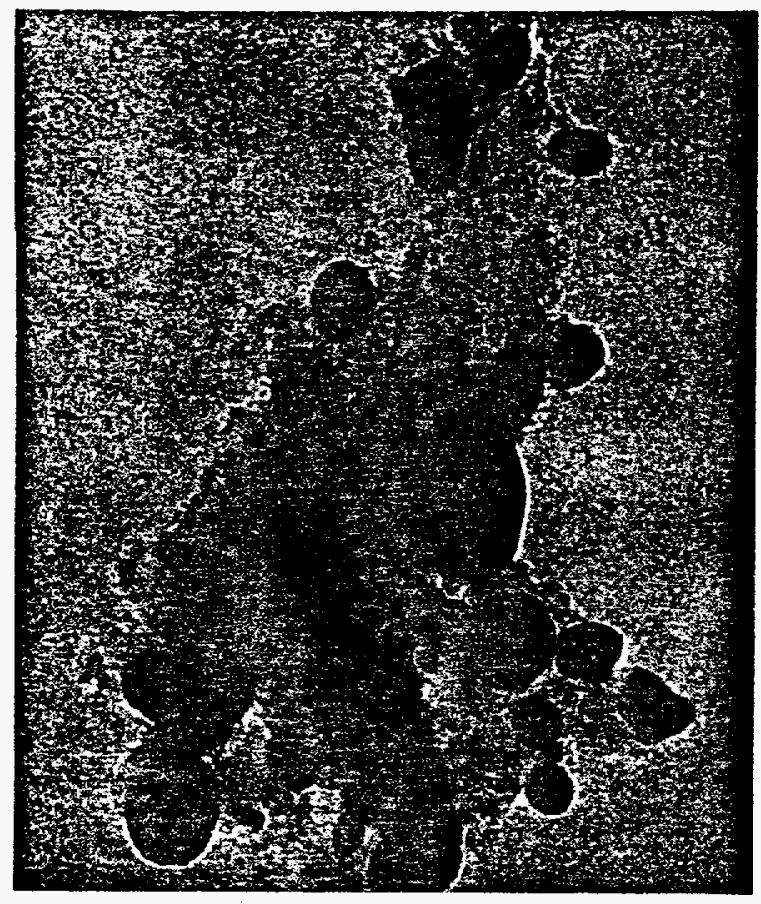

$100 \mathrm{~nm}$

Figure 4. Fragment scraped from sample treated in ammonia solution for 48 hours.

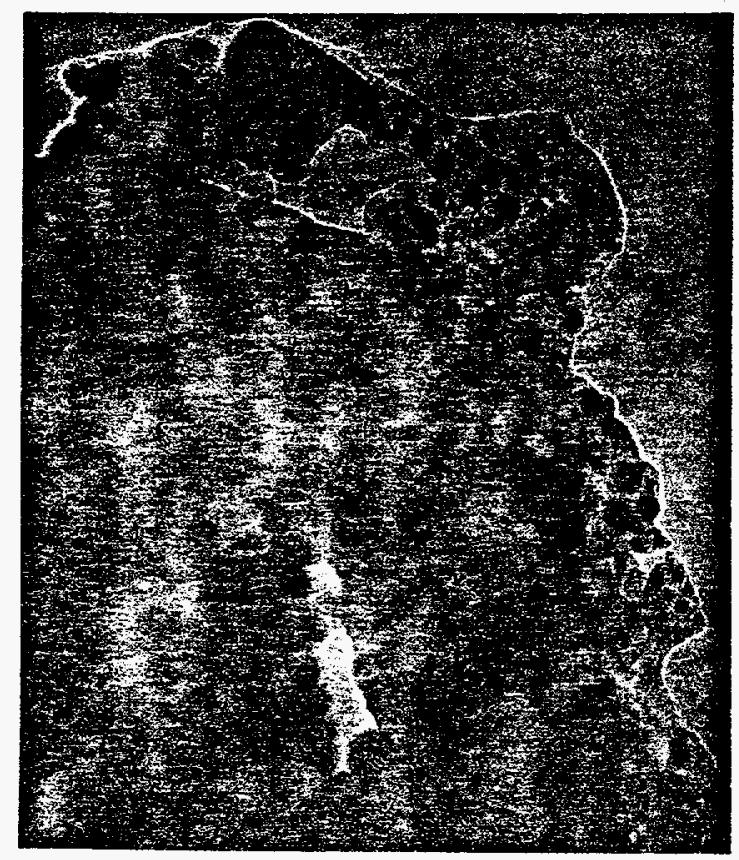

$-100 \mathrm{~nm}$

Figure 6. Region of surface of cross-sectional specimen treated in $0.01 \mathrm{M} \mathrm{H}_{2} \mathrm{SO}_{4}$ for 72 hours.

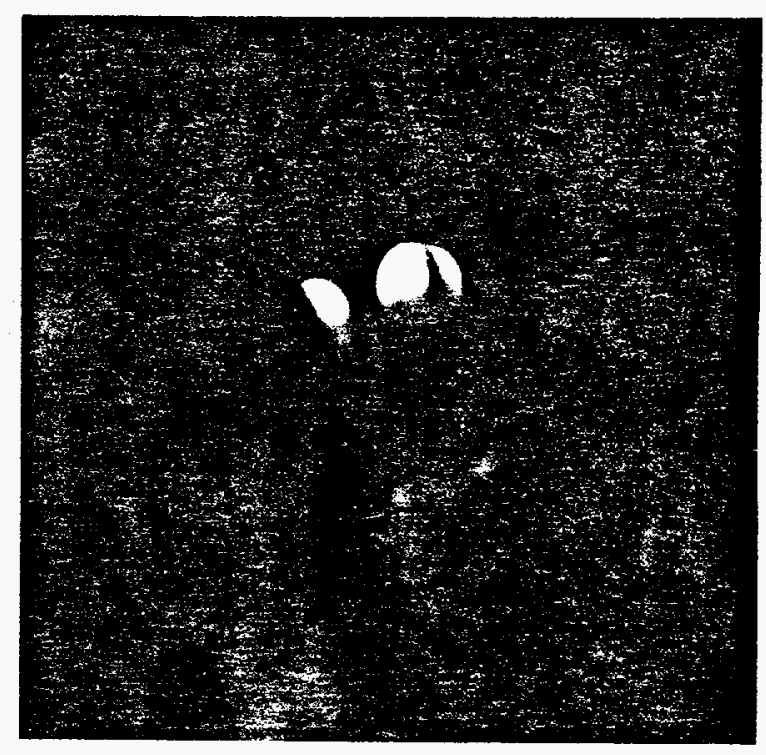

Figure 5. Convergent beam diffraction pattern from one particle in fragment shown in Fig. 4.

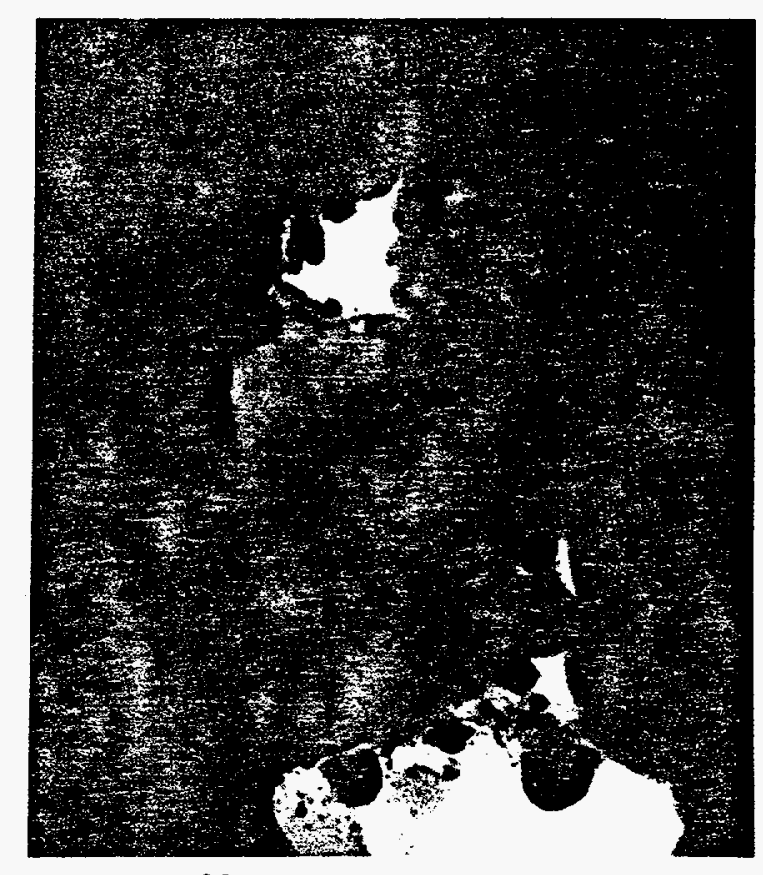

$100 \mathrm{~nm}$

Figure 7. Region of surface of cross-sectional specimen treated in $0.01 \mathrm{M} \mathrm{H}_{2} \mathrm{SO}_{4}$ for 72 hours. 


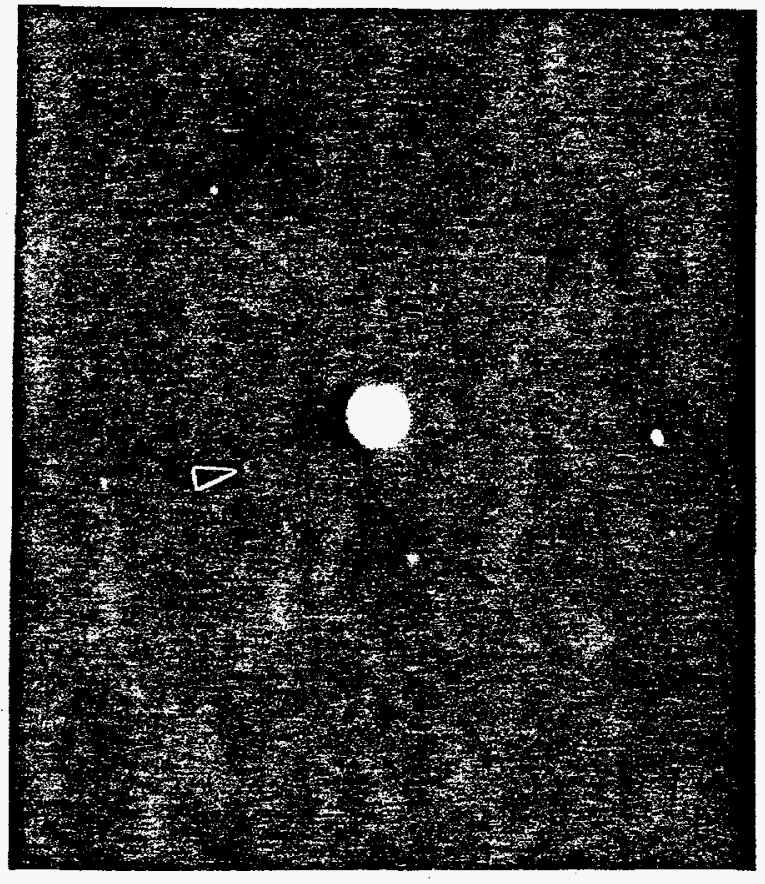

Figure 8. Selected area diffraction pattern taken from region shown in Fig. 7.

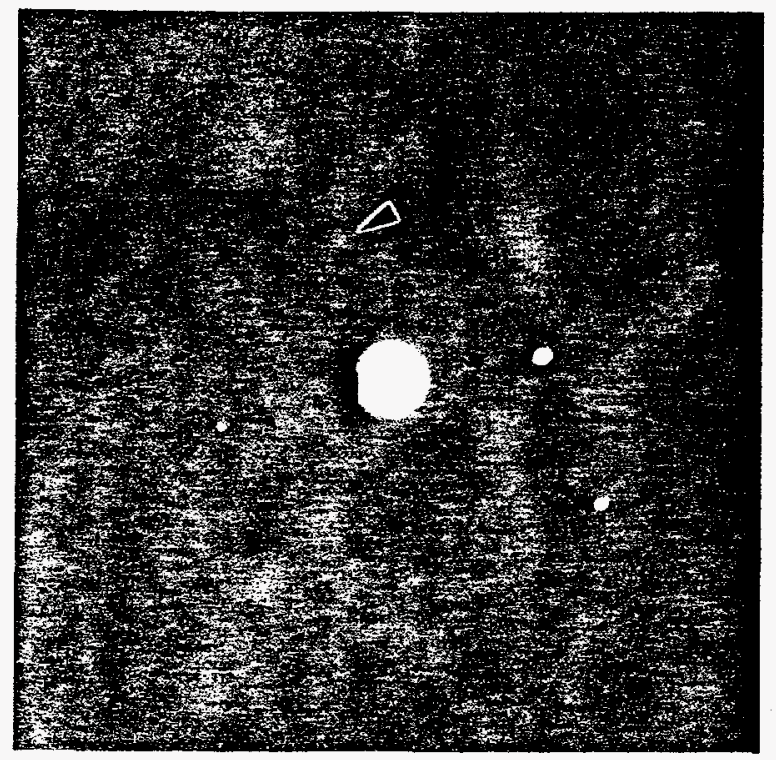

Figure 10. Selected area diffraction pattern. The indicated beam was used to create the dark field image shown in Fig. 11.

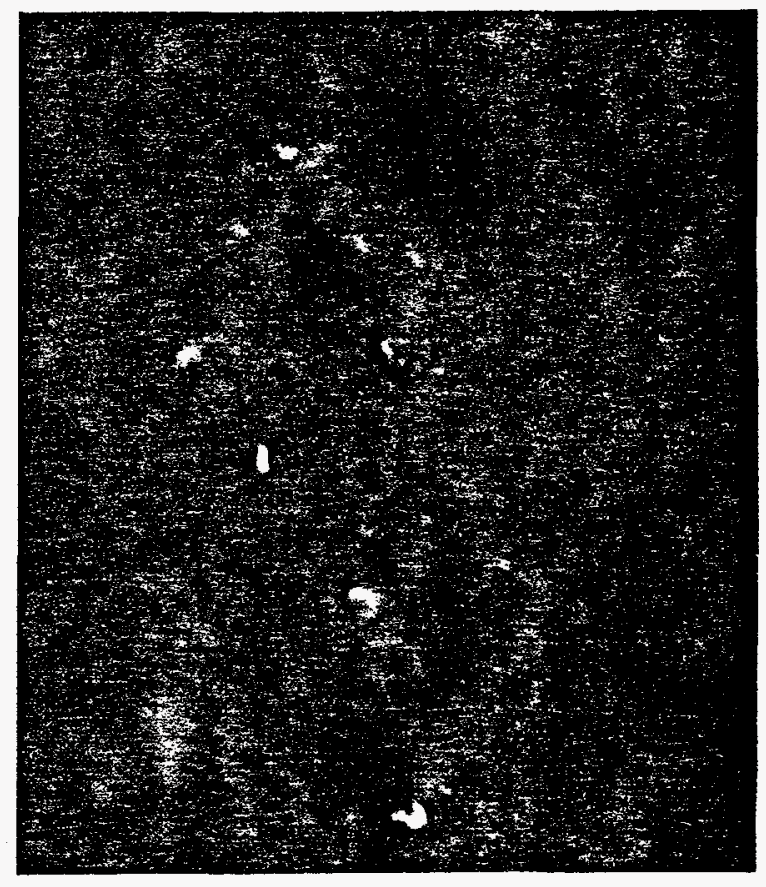

$100 \mathrm{~nm}$

Figure 9. Dark field image of region shown in Fig. 7. The beam used to create the image is indicated in Fig. 8.

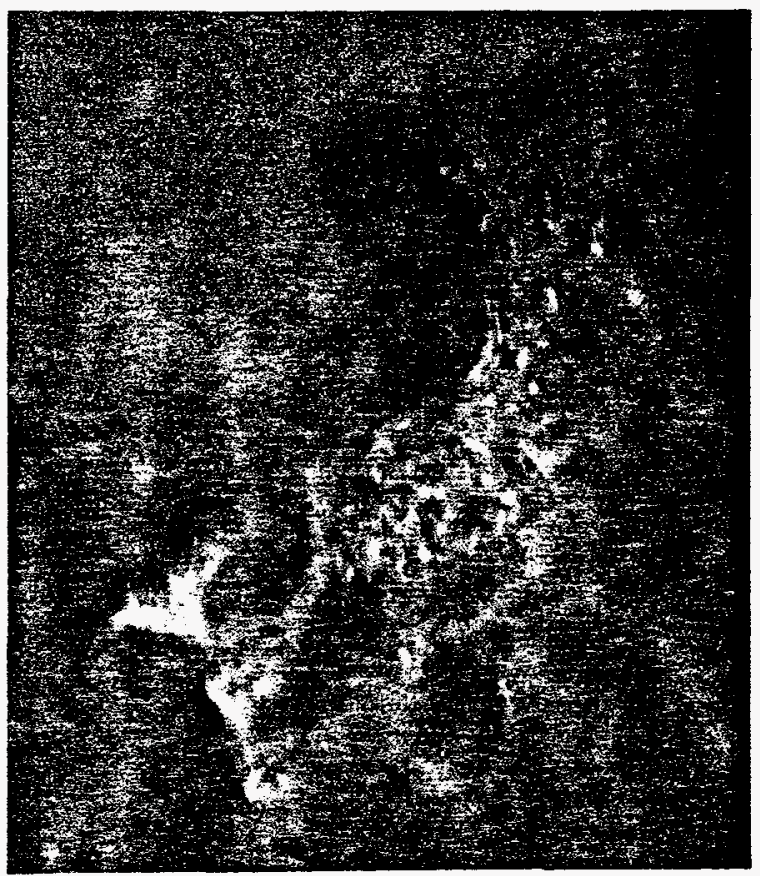

$100 \mathrm{~nm}$

Figure 11. Dark field image of region of surface of cross-sectional specimen treated in $0.01 \mathrm{M}$ $\mathrm{H}_{2} \mathrm{SO}_{4}$ for 72 hours. 
measured spacings are shown in Figure 3(c). The broad band at the center is indicated by its endpoints. The substance that made the pattern appears to be the $\delta$ phase. A dark field image formed from with the spot at $2.1 \dot{A}$ is shown in Figure 11. Small, bright spots are again visible.

\section{DISCUSSION}

The previous TEM work proposed that the $\alpha$-phase replacement product was $\mathrm{Sn}_{1-x}(\mathrm{Cu}, \mathrm{Fe}, \mathrm{Pb}, \mathrm{Si})_{x} \mathrm{O}_{2}$ having the cassiterite structure with some of the tin atoms substituted by copper, iron, lead and/or silicon. ${ }^{6}$ These conclusions were based mainly on diffraction patterns corresponding to a cassiterite structure combined with electron microprobe detection of the other species. The presence of copper may be explained by the small particles apparently of one of the alloy phases found among the tin oxide crystals in the replicated altered region.

\section{CONCLUSIONS}

1. Tin oxide has been detected on the surfaces of both ancient Chinese mirrors and model treated bronze samples. The tin oxide takes a nanocrystalline spheroidal form in the model samples.

2. Small particles of remnant alloy phase have been found interspersed with the tin oxide crystals.

\section{ACKNOWLEDGMENTS}

This work was performed in part under the auspices of the U. S. Department of Energy, Division of Materials Sciences, Office of Basic Energy Sciences under Contract No. DE-AC0276CH00016. We would like to express our gratitude to Kenneth Sutter for casting the bronze and Fred Chen and Phillip Wang for pointers on sample preparation.

\section{REFERENCES}

1. W.F. Collins, J. Royal Anthrop. Inst. 64, 69-79 (1934).

2. R.J. Gettens, Technical Studies in the Field of Fine Arts III(1), 29-37 (1934).

3. W.T. Chase and U.M. Franklin, Ars Orientalis XI, 215-258 (1979).

4. S. Zhu and T. He in Metal Plating and Patination - Cultural, Technical and Historical Developments, edited by S. La Niece and P. Craddock (Butterworth-Heinemann Lid., Oxford, 1993), pp. 51-62.

5. N. Meeks in Metal Plating and Patination - Cultural, Technical and Historical Developments, edited by S. La Niece and P. Craddock (Butterworth-Heinemann Ltd., Oxford, 1993), pp. 63-84.

6. C. Wang, B. Lu, J. Zuo, S. Zhang, S. Tan, M. Suzuki, W.T. Chase, NanoStruct. Mater. 5(4), 489-496 (1995).

7. S. Sun, Z. Ma, L. Jin, R. Han, T. Ko, "The formation of black patina on bronze mirrors: the action of humic acid," (unpublished translation).

8. R.J. Gettens, Bulletin of the Fogg Art Museum 11(1), 16-26 (1949).

9. R.J. Gettens, The Freer Chinese Bronzes, Vol. II, Technical Studies, (Smithsonian Institution, Washington, D.C., 1969), pp. 186-191.

10. R.J. Gettens in Ant and Technology; A Symposium on Classical Bronzes, edited by Suzannah Doeringer (MIT Press, Cambridge, MA, 1970), pp. 57-72.

11. M. Taube, A.J. Davenport, A.H. King, W.T. Chase in Aqueous Chemistry and Geochemistry of Oxides, Oxyhydroxides, and Related Materials, edited by J. Voigt, B. Bunker, W. Casey, T. Wood, and L. Crossey (Mater. Res. Soc. Proc. 432, Pittsburgh, PA), in press.

12. M. Taube, W.T. Chase, A.J. Davenport, A.P. Jardine in Materials Issues in Art and Archaeology IV. edited by P. Vandiver, J. Druzik, J.L. Galvan, I. Freestone and G.S. Wheeler (Mater. Res. Soc. Proc. 352, Pittsburgh, PA, 1995), pp. 215-221. 